\title{
SILÍCIO NA EFICIÊNCIA DE Azospirillum brasilense EM TRIGO
}

\author{
Tamires Esther Ferreira ${ }^{1}$, Miriam Büchler Tarumoto ${ }^{2}$, Lais Bilia Picoli ${ }^{1}$, Virley Gardeny \\ Lima Sena ${ }^{2}$
}

\footnotetext{
${ }^{1}$ Mestranda no Programa de Agricultura, Departamento de Produção Vegetal - Faculdade de Ciências Agronômicas (FCA) /Universidade Estadual Paulista (UNESP), Botucatu (SP). Email: teferreira.agro@gmail.com; lais_bp@hotmail.com

${ }^{2}$ Doutoranda no Programa de Agricultura, Departamento de Produção Vegetal - Faculdade de Ciências Agronômicas (FCA) /Universidade Estadual Paulista (UNESP), Botucatu (SP). Email: miriamtarumoto@gmail.com; virleysena@gmail.com
}

RESUMO: O trabalho teve como objetivo avaliar a ação do silício durante o desenvolvimento inicial de plantas de trigo inoculadas com Azospirillum brasilense. A pesquisa compreendeu o ano agrícola 2015, testando dois corretivos agrícolas (calcário dolomítico e silicato de cálcio e magnésio), quatro métodos de inoculação (ausente, sulco, sulco/foliar e foliar) da estirpe $\mathrm{Ab}-\mathrm{V}_{5}$ de Azospirillum brasilense e um controle, compondo fatorial $4 \times 2+1$ em delineamento inteiramente casualizado com quatro repetições. Foram avaliados índice de velocidade de emergência (IVE), altura de plantas (cm), volume de raiz $(\mathrm{mL})$, número de perfilhos e folhas por planta $\left(\mathrm{n}^{\circ}\right.$ planta $\left.^{-1}\right)$, e quantidade de nitrogênio e silício de parte aérea e raiz $\left(\mathrm{g} \mathrm{kg}^{-1}\right)$. A inoculação em sulco e foliar promove o acumulo de nitrogênio na parte aérea, mas reduz o número de perfilhos, que se reproduz sobre a menor produção de matéria seca desta região. O silício incrementa a altura de plantas de trigo, melhora a eficiência de absorção de nitrogênio na parte aérea e não restringe a atividade do Azospirillum brasilense, independente do método de inoculação, podendo ser empregado como insumo adicional à cultura.

Palavras-chave: Triticum aestivum. Adubação silicatada. Bactéria promotora de crescimento de plantas (BPCP).

\section{SILICON EFFICIENCY ON Azospirillum brasilense IN WHEAT PLANTS}

\begin{abstract}
The study aimed to evaluate silicon effect on Azospirillum brasilense behavior in wheat plants. The experiment was carried out along 2015 crop season under Cwa climate. Were tested two types of acidity correctives (dolomitc limestone and calcium silicate), four inoculation methods (absent, furrow, furrow+leaf and leaf) of $\mathrm{Ab}-\mathrm{V}_{5} \mathrm{de}$ Azospirillum brasilense straim, plus control, composing factorial $4 \times 2+1$ with 4 replications.Were assessed: emergence speed index $(E S I)$, height $(\mathrm{cm})$, number of tillers and leaves per plant $\left(\mathrm{n}^{\circ}\right.$.plant $\left.{ }^{-1}\right)$, nitrogen and silicon content in leaves and roots $\left(\mathrm{g} \cdot \mathrm{kg}^{-1}\right)$. We concluded according to the study wheat plants can be compromised by decreasing its tillering and dry matter production of leaves, mainly by forrow+leaf inoculation, wich, in other hand, increases nitrogen content in leaves. Silicated fertilization increases plants
\end{abstract}

Cultura Agronômica, Ilha Solteira, v.26, n.3, p.393-405, 2017 
height, improves nitrogen uptake and does not interfer on Azospirillum brasilense activity and can be used as additional input with bacteria on wheat crop.

Key words: Triticum aestivum. Silicated fertilization. Plant growth promoting bacteria (PGPB).

\section{INTRODUÇÃO}

O trigo (Triticum aestivum), é um dos cereais mais produzidos no mundo. Graças à diversidade genética e qualidade nutricional dos grãos, a cultura alimenta cerca de 1/3 da população mundial (SLEPER; POEHLMAN, 2006). Tendo em vista que para o ano de 2100 a população atinja 10,9 bilhões de habitantes (ALVES, 2014), garantir a produtividade agrícola é um desafio que envolve atender a demanda crescente por alimento, e aliar, sobretudo, o manejo racional de nutrientes com o mínimo de impacto ambiental.

O silício ( $\mathrm{Si}$ ), apesar de não ser considerado como elemento essencial as plantas (LIANG et al., 2015), tem se mostrado importante para as mesmas. Contribui na redução da taxa de transpiração, tolerância ao estresse hídrico, injúria por metais tóxicos (MORO et al. 2015; PRABAGAR et al. 2011; CASTRO; CRUSCIOL, 2013), inclusive é capaz de se depositar na parede celular (MA; YAMAJI, 2006), formando uma barreira mecânica à invasão de fungos e bactérias, e ao ataque de insetos praga (COSTA et al., 2009).

O questionamento acerca deste elemento se estende a necessidade de elucidar sua atuação quanto à entrada de bactérias benéficas ou denominadas bactérias promotoras de crescimento de plantas (BPCP).

A espécie Azospirillum brasilense vem sendo amplamente estudada como BPCP e diazotrófica (BASHAN; BASHAN, 2010), embora ofereça benefícios adicionais como a secreção de fitormônios (MOREIRA et al., 2010), controle biológico e a vantagem de estar amplamente distribuída em diferentes solos e climas (ARAÚJO, 2008).

Tais características a tornam atrativa para a triticultura, que já presencia ganhos em produção (HUNGRIA, 2011), inclusive servindo para complementar a adubação nitrogenada (HUNGRIA et al., 2010), o que a configura como uma tecnologia promissora, pouco onerosa e de baixo impacto ambiental.

Diante das informações, o objetivo do estudo foi avaliar a ação do silício sobre o desempenho de Azospirillum brasilense no desenvolvimento inicial de plantas de trigo.

\section{MATERIAL E MÉTODOS}

O experimento foi desenvolvido no município de Botucatu - SP, localizado a $22^{\circ} 52^{\prime}$ $55^{\prime}$ ' S e 48 26' 22" O, e a 789 m de altitude, durante o período de junho a julho de 2015 . O clima local é do tipo temperado quente (mesotérmico), segundo Köppen, com temperatura 
média diária do mês mais frio (Julho) de $17,1^{\circ} \mathrm{C}$ e a do mês mais quente (Fevereiro) de 23,3 ${ }^{\circ} \mathrm{C}$, com precipitação média anual de 1314 mm (CUNHA; MARTINS, 2009).

Os dados de temperatura diária foram coletados de termômetro, localizado no interior da estufa, e a evapotranspiração diária foi medida pelo tanque classe A. Este método mede o efeito integrado da radiação solar, velocidade do vento, temperatura e umidade relativa sobre a evaporação de uma superfície de água livre, fornecendo os dados conforme descritos na Figura 1.

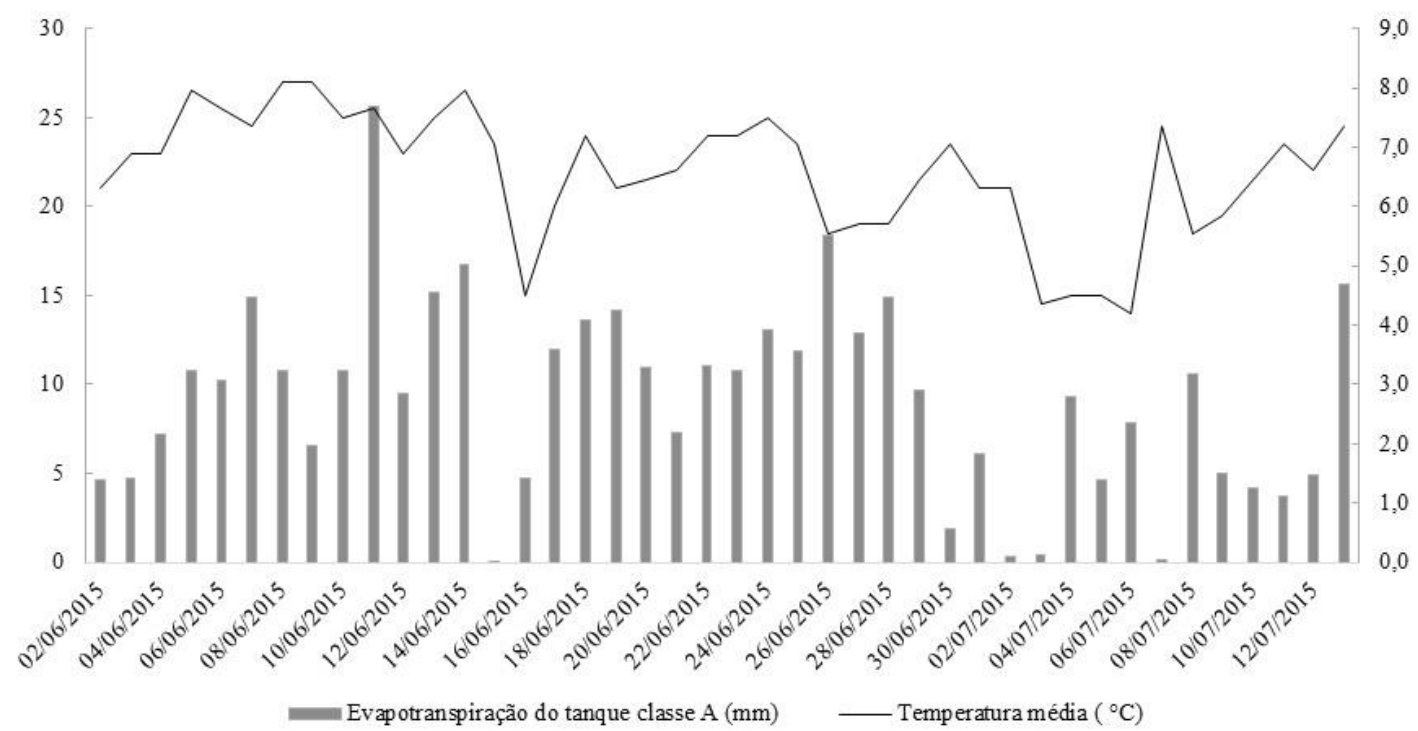

Figura 1. Temperatura média e evaporação do tanque classe A registradas durante o período experimental

O delineamento experimental utilizado foi inteiramente casualizado em esquema fatorial $4 \times 2+1$. O primeiro fator se refere aos métodos de inoculação (ausente, sulco, sulco/foliar e foliar) da estirpe $\mathrm{Ab}^{-\mathrm{V}_{5}}$ de Azospirillum brasilense; o segundo fator corresponde as fontes corretivas (silicato de cálcio e magnésio e calcário dolomítico), mais controle, com quatro repetições, totalizando 36 unidades experimentais.

A unidade experimental foi composta por vasos de polietileno de $5 \mathrm{~L}$, recebendo $4,5 \mathrm{~L}$ de terra fina seca ao ar (TFSA), peneirada em malha de $5 \mathrm{~mm}$ e coletada da camada arável $(0,00-0,20 \mathrm{~m})$ de área adjacente em pousio.

O solo da região é o Latossolo vermelho de textura argilosa (539 $\mathrm{g} \mathrm{kg}^{-1}$ de argila; $297 \mathrm{~g}$ $\mathrm{kg}^{-1}$ de areia e $164 \mathrm{~g} \mathrm{~kg}^{-1}$ de silte), cujas características químicas são descritas por: $\mathrm{pH}_{\mathrm{CaCl} 2}=$ 5,$2 ; \mathrm{MO}=23 \mathrm{~g} \mathrm{~kg}^{-1} ; \mathrm{P}=28 \mathrm{mg} \mathrm{dm}^{-3} ; \mathrm{Al}^{+3}=0 ; \mathrm{H}+\mathrm{Al}^{+3}=35 \mathrm{mmol}_{\mathrm{c}} \mathrm{dm}^{-3} ; \mathrm{K}=4,5 \mathrm{mmol}_{\mathrm{c}} \mathrm{dm}^{-3}$; $\mathrm{Ca}=32 \mathrm{mmol}_{\mathrm{c}} \mathrm{dm}^{-3} ; \mathrm{Mg}=13 \mathrm{mmol}_{\mathrm{c}} \mathrm{dm}^{-3} ; \mathrm{Si}=0,12 \mathrm{mmol}_{\mathrm{c}} \mathrm{dm}^{-3} ; \mathrm{SB}=49 \mathrm{mmol}_{\mathrm{c}} \mathrm{dm}^{-3} ; \mathrm{CTC}=$ $84 \mathrm{mmol}_{\mathrm{c}} \mathrm{dm}^{-3}$ e V\%= 58 .

O silício foi aplicado com o intuito de elevar o teor do elemento no solo a $0,35 \mathrm{mmol}_{\mathrm{c}}$ $\mathrm{dm}^{-3}$ (10 $\mathrm{mg} \mathrm{dm}^{-3}$ ) seguindo recomendação de Snyder (1991), e o calcário foi calculado conforme informações técnicas de adubação para trigo, depositando em cada vaso o 
equivalente a 2,04g. Foram utilizados, neste momento, superfosfato triplo, cloreto de potássio, e ureia nas doses de 1,33, 1,74 e 1,22 g, respectivamente (EMBRAPA, 2014). O solo e os insumos foram misturados em betoneira de $260 \mathrm{~L}$ para distribuir e homogeneizar de forma eficiente todos os componentes.

Como fonte de Si foi utilizado o produto comercial Agrossilício ® com 34,9\% CaO, $22,4 \% \mathrm{SiO}_{2}$ e $9,9 \% \mathrm{MgO}$ e PRNT=85\%, e o calcário selecionado com $32 \% \mathrm{CaO}$ e $18 \%$ $\mathrm{MgO}$ e PRNT $=90 \%$, classificado como dolomítico. A fonte calcária serviu para neutralizar os efeitos do cálcio e magnésio presente na constituição do silicato, buscando preservar e isolar apenas os resultados referentes à ação do silício sobre o Azospirillum.

A semeadura foi realizada em 02/06/2015, fornecendo por vaso 15 sementes do cultivar Coodetec 103, obtida pela COODETEC - Cooperativa Central Agropecuária de Desenvolvimento Tecnológico e Econômico Ltda.

A inoculação no sulco de semeadura foi administrada em seguida, com a deposição do inoculante Nodu Gram L, como fonte de Azospirillum brasilense, estirpe Ab- $\mathrm{V}_{5}$, contendo 2 x $10^{8}$ células viáveis por $\mathrm{mL}$, dos quais se aplicou sobre a superfície das sementes, com pipeta automática de $10 \mu \mathrm{L}$, a dose de $0,025 \mathrm{~mL}$, obedecendo a proporção de $100 \mathrm{~mL}$ para 60.000 sementes. Procedeu-se o desbaste de 4 plantas por vaso, conduzindo-se o total de 11 plantas por unidade experimental, de onde foi possível determinar durante sete dias, o índice de velocidade de emergência, obedecendo a relação: número acumulado de plântulas emergidas/número de dias contados após a semeadura.

A inoculação foliar foi realizada 21 dias após a semeadura (23/06/2015) seguindo o mesmo procedimento em sulco, entretanto, o produto foi administrado ao final da tarde, buscando elevar a eficiência do inoculante.

Na ocasião da colheita, em 13/07/2015, foi determinada a altura de plantas com auxílio régua graduada, e o número de perfilhos, pela contagem manual das estruturas. $\mathrm{O}$ volume de raiz seguiu o método de deslocamento de líquido em proveta (BASSO, 1999). As plantas foram compartimentalizadas em partes aérea e raiz, acondicionadas em saco de papel e secas em estufa de circulação forçada à temperatura de $65-70{ }^{\circ} \mathrm{C}$ até atingir peso constante. $O$ material vegetal foi pesado em balança de precisão $(0,001 \mathrm{~g})$ para determinação da matéria seca de parte aérea e radicular. As amostras foram processadas em moinho tipo Willey para determinação de nitrogênio $(\mathrm{N})$, pela metodologia de Kjeldahl, conforme proposto por Galvani e Gaertner (2006) e silício ( $\mathrm{Si}$ ), segundo método proposto por Korndörfer et al. (2004).

Os dados foram submetidos a análise de variância (ANOVA) e as médias significativas, foram analisadas pelo teste LSD a 5\% de confiabilidade $(\mathrm{p}<0,05)$, usando o pacote estatístico SISVAR. Para a análise simultânea dos fatores (corretivo e método de inoculação) + controle, a comparação entre os dados foi submetida ao teste de Dunnet $(\mathrm{p}<0,05)$.

Cultura Agronômica, Ilha Solteira, v.26, n.3, p.393-405, 2017 


\section{RESULTADOS E DISCUSSÃO}

De acordo com os parâmetros de crescimento e variáveis nutricional, houve influência da adubação silicatada sobre a altura das plantas e o acúmulo de nitrogênio na parte aérea, embora para as demais variáveis não foi detectada diferença significativa entre os corretivos (Tabela 1).

Tabela 1. Médias gerais do índice de velocidade de emergência (IVE), número de perfilhos por planta (Npp), número de folhas por planta (Fp), altura por planta (Alt), volume radicular (Vol), matéria seca da parte aérea (MSpa), matéria seca radicular (MSr), quantidade de na parte aérea (Npa), quantidade de nitrogênio radicular $(\mathrm{Nr})$, quantidade de silício na parte aérea (Spa) e quantidade de silício radicular ( $\mathrm{Sr}$ ) avaliadas para os corretivos e métodos de inoculação ${ }^{1}$.

\begin{tabular}{|c|c|c|c|c|c|c|c|c|c|c|c|}
\hline Tratamentos & IVE & \multicolumn{2}{|c|}{$\begin{array}{l}\text { Npp Fp } \\
\text { n }^{\text {o }} \text { planta }^{-1}\end{array}$} & $\begin{array}{l}\text { Alt } \\
\mathrm{cm}\end{array}$ & $\begin{array}{c}\text { Vol } \\
\mathrm{ml}\end{array}$ & \multicolumn{2}{|c|}{$\begin{array}{c}\text { MSpa MSr } \\
\text { g }\end{array}$} & \multicolumn{4}{|c|}{$\begin{array}{l}\mathrm{Nr} \mathrm{g} \mathrm{kga}^{-1} \\
\text { Spa }\end{array}$} \\
\hline Fonte & & & & & & & & & & & \\
\hline Controle & 6,94 & 1,86 & 7,07 & 33,54 & 18,2 & 1,98 & 1,89 & 32,32 & 11,01 & 9,87 & 14,94 \\
\hline P & ns & 0,013 & $\mathrm{~ns}$ & ns & $\mathrm{ns}$ & 0,006 & $\mathrm{~ns}$ & 0,00 & $\mathrm{~ns}$ & $\mathrm{~ns}$ & ns \\
\hline Calcário & 5,77 & 1,30 & 6,31 & $31,6 \mathbf{b}$ & 17,1 & 1,66 & 1,70 & $31,9 \mathbf{b}$ & 10,70 & 9,82 & 15,71 \\
\hline Silício & 6,12 & 1,43 & 6,40 & $33,9 \mathbf{a}$ & 20,3 & 1,78 & 1,74 & $34,6 \mathbf{a}$ & 10,8 & 9,47 & 15,45 \\
\hline D.M.S & 1,1 & 0,21 & 0,43 & 1,72 & 5,95 & 0,20 & 0,25 & 2,3 & 1,13 & 1,3 & 1,46 \\
\hline \multicolumn{12}{|l|}{$\begin{array}{l}\text { Inoculação } \\
\text { (ml/semente) }\end{array}$} \\
\hline Ausente & 7,23 & 1,56 & 6,75 & 32,98 & 21,5 & $2,0 \mathbf{a}$ & 1,88 & $29,1 \mathbf{b}$ & $9,74 \mathbf{b}$ & 10,1 & 14,99 \\
\hline Sulco & 5,98 & 1,40 & 6,38 & 32,43 & 16,7 & $1,7 \mathbf{a b}$ & 1,92 & $31,2 \mathbf{b}$ & $10,1 \mathbf{a b}$ & 9,56 & 14,89 \\
\hline Sulco/Foliar & 5,29 & 1,20 & 6,00 & 31,68 & 18,3 & $1,5 \mathbf{b}$ & 1,53 & $35,5 \mathbf{a}$ & $11,4 \mathbf{a}$ & 10,4 & 16,27 \\
\hline Foliar & 5,29 & 1,30 & 6,30 & 33,76 & 18,2 & $1,6 \mathbf{b}$ & 1,55 & $37,4 \mathbf{a}$ & $11,7 \mathbf{a}$ & 8,49 & 16,17 \\
\hline $\mathrm{F}$ & ns & $\mathrm{ns}$ & ns & 0,01 & ns & $\mathrm{ns}$ & $\mathrm{ns}$ & 0,02 & $\mathrm{~ns}$ & $\mathrm{~ns}$ & ns \\
\hline I & $\mathrm{ns}$ & ns & ns & ns & ns & 0,00 & ns & 0,000 & 0,04 & ns & ns \\
\hline FxI & ns & ns & ns & ns & ns & ns & ns & ns & $\mathrm{ns}$ & $\mathrm{ns}$ & ns \\
\hline CV (\%) & 25,1 & 21,5 & 9,4 & 7,2 & 42 & 15,9 & 20,5 & 9,5 & 14 & 17,1 & 12,8 \\
\hline D.M.S & 1,5 & 0,30 & 0,62 & 2,43 & 2,88 & 0,3 & 0,36 & 3,24 & 1,6 & 1,7 & 2,06 \\
\hline
\end{tabular}

${ }^{1}$ ns - Não significativo. Médias seguidas com a mesma letra não diferem estatisticamente entre si pelo teste $\operatorname{LSD}(\mathrm{p}<0,05)$

As plantas que receberam silicato foram sensivelmente superiores ao controle, e acumularam ao final do experimento mais nitrogênio na parte aérea $\left(34,6 \mathrm{~g} \mathrm{~kg}^{-1}\right)$ comparado ao tratamento com calcário $\left(31,9 \mathrm{~g} \cdot \mathrm{kg}^{-1}\right)$. Por ser uma espécie naturalmente acumuladora de $\mathrm{Si}$, presume-se que a importância deste elemento para o trigo tenha sido mais expressiva e revertida sobre a arquitetura e nutrição destas plantas.

Neste caso, a alta solubilidade do silicato de $\mathrm{Ca}$ e $\mathrm{Mg}$, que chega a ser 6,78 vezes maior que o calcário (ALCARDE; RODELLA, 2003), em um menor período de tempo, 
pode ter contribuído para uma disponibilidade mais rápida do nitrogênio às plantas, que para alguns autores pode ser justificado pela elevação do $\mathrm{pH}$, CTC e V\% do solo (CASTRO; CRUSCIOL, 2013). O benefício entre adubação silicatada e fornecimento de $\mathrm{N}$ também foi notificada em cana-de-açúcar (BASTO et al., 2010), e leguminosas (FONSECA et al., 2011), ressaltando a importância e divulgação desta fonte corretiva sobre a eficiência de $\mathrm{N}$ às culturas em geral.

O silicato também influenciou a estrutura das plantas de trigo, que foram $7 \%$ mais altas em relação às plantas tratadas com calcário, apesar de não ser estaticamente detectada diferença para variáveis relacionadas ao crescimento vegetal, como volume radicular, número de folhas e perfilhos por planta (Tabela 1).

Depois de absorvido pela planta, o Si é depositado principalmente na parede celular, aumentando a rigidez dos tecidos (MA; YAMAJI, 2006), por exemplo, de folhas e colmos, como foi verificado por Singh et al. (2005). Para Epstein (1999), a presença do Si está associada a propriedade de alterar a arquitetura das plantas modificando o ângulo foliar, o que permite a intensificação e interceptação luminosa e maior taxa fotossintética, concordando com observações de Malavolta (2006). Por outro lado, para Lima Filho et al. (2007), a promoção do crescimento de plantas tratadas com Si em trigo e maioria das gramíneas, está atrelada ao aumento do tamanho das células, ou seja, atuando no alongamento celular, uma plausível explicação para o resultado verificado no estudo.

A produção de matéria seca da parte aérea não sofreu influência independente do método de inoculação adotado, mas foi possível verificar o efeito dos tratamentos inoculados via foliar sobre a quantidade de nitrogênio acumulado na parte aérea e radicular (Tabela 1).

Em geral, as plantas que receberam inoculação em sulco/foliar e foliar, acumularam em média 21 e $18 \%$ mais $\mathrm{N}$ na parte aérea e raiz, respectivamente, comparado ao tratamento ausente.

O resultado pode ser atribuído a notória contribuição da Azospirillum na fixação biológica de nitrogênio (BASHAN et al., 2012), que vem sendo relatado especialmente em espécies gramíneas, como as culturas de milho, cana-de-açúcar, inclusive para trigo (HUNGRIA et al., 2010; SCHULTZ et al., 2014; PORTUGAL et al., 2016).

A aplicação do teste de Dunnet revelou influência, sobretudo, do método de inoculação sobre a quantidade de nitrogênio da parte aérea e número de perfilhos, e a hipótese inicial de que o silício impediria a penetração da bactéria passa a ser revogada, uma vez que a fonte silicatada se comportou similar ao calcário para as variáveis analisadas, confirmando que não interfere sobre a atividade bacteriana (Figura 2A e 2B). 


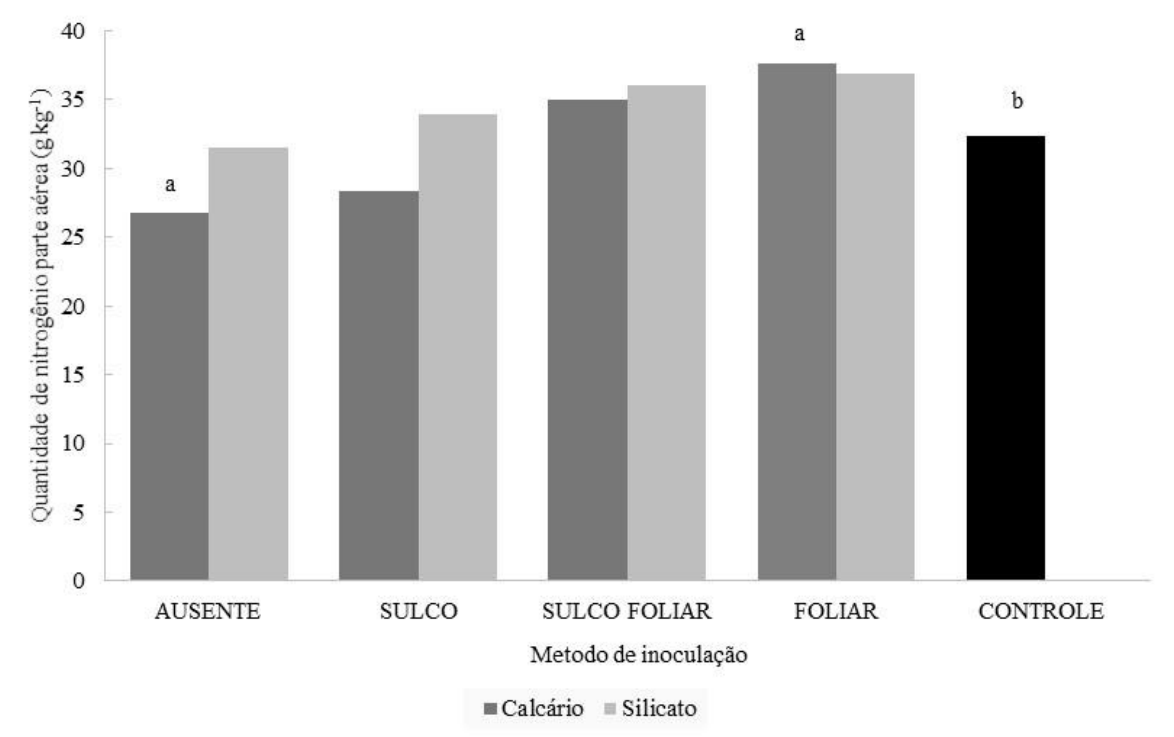

(A)

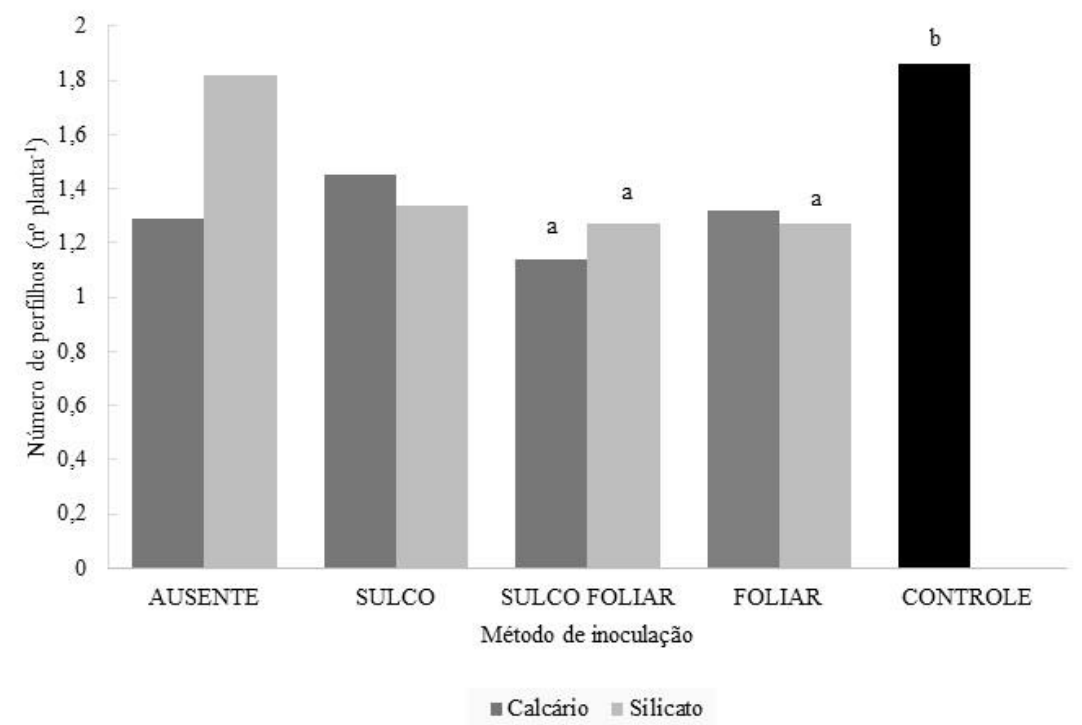

(B)

Médias com letras diferentes entre colunas diferem significativamente do controle pelo teste de Dunnet $(\mathrm{p}<$ $0,05)$.

Figura 2. Plantas de trigo adubadas em presença de silício e calcário associado aos métodos de inoculação com Azospirillum brasilense referente às variáveis: A. quantidade de nitrogênio da parte aérea $B$. número de perfilhos por planta.

Normalmente a inoculação com Azospirillum é administrada simultaneamente ao tratamento de sementes. Porém, de acordo com Fukami et al. (2016), pouco se sabe sobre o efeito que os pesticidas usados como acompanhamento provocam nesta bactéria. Os autores relatam que métodos alternativos de inoculação nas culturas são necessários, e destacam a inoculação foliar na fase vegetativa. Por outro lado, Zilli et al. (2010) sugerem a inoculação no sulco de semeadura ao invés de inoculação em sementes, sendo esta prática tecnicamente recomendada (EMBRAPA, 2011).

Cultura Agronômica, Ilha Solteira, v.26, n.3, p.393-405, 2017 
Conforme verificado no estudo, ambos os tratamentos foram benéficos, incluindo a reinoculação sulco/foliar (SF) e apenas foliar $(\mathrm{F})$, que reverteram em maior quantidade de nitrogênio na parte aérea, registrando diferença de 55\% para SF e $43 \%$ para F comparado ao controle (ausente de corretivo e inoculação).

A atividade diazotrófica da bactéria pode ser constatada, considerando que para todos os métodos de inoculação a quantidade de $\mathrm{N}$ não apresentou diferença significativa do controle, com exceção do tratamento ausente, embora todos os valores se encontravam dentro da faixa adequada para a cultura (20 a $34 \mathrm{~g} \mathrm{~kg}^{-1}$ de N) segundo Cantarella e Raij (1997).

Entre os métodos de inoculação avaliados, o fornecimento da bactéria via SF em presença de calcário ou silício provocou menor produção no número de perfilhos em relação às plantas controle (Figura 2B).

Para Assuero e Tognetti (2010), o processo de perfilhamento é controlado por diferentes mecanismos, incluindo o fator hormonal, que regula os processos de dominância apical e superação de dormência em gemas laterais. Como normalmente os hormônios vegetais são expressos em baixa concentração, a reinoculação, segundo Dobbelaere et al. (2002), pode ter efeitos negativos sobre o crescimento de plantas, que é justificado pelo aumento da dose. Sendo assim, a penetração do Azospirillum pelas raízes (NABTI et al., 2010) e folhas (BASHAN, 1998), favorecido no tratamento SF, pode ter intensificado a população da bactéria no tecido vegetal, e desestabilizado o nível hormonal da planta, uma vez que, entre outros mecanismos associados a bactéria, incluem a secreção de fitormonios (MOREIRA et al., 2010).

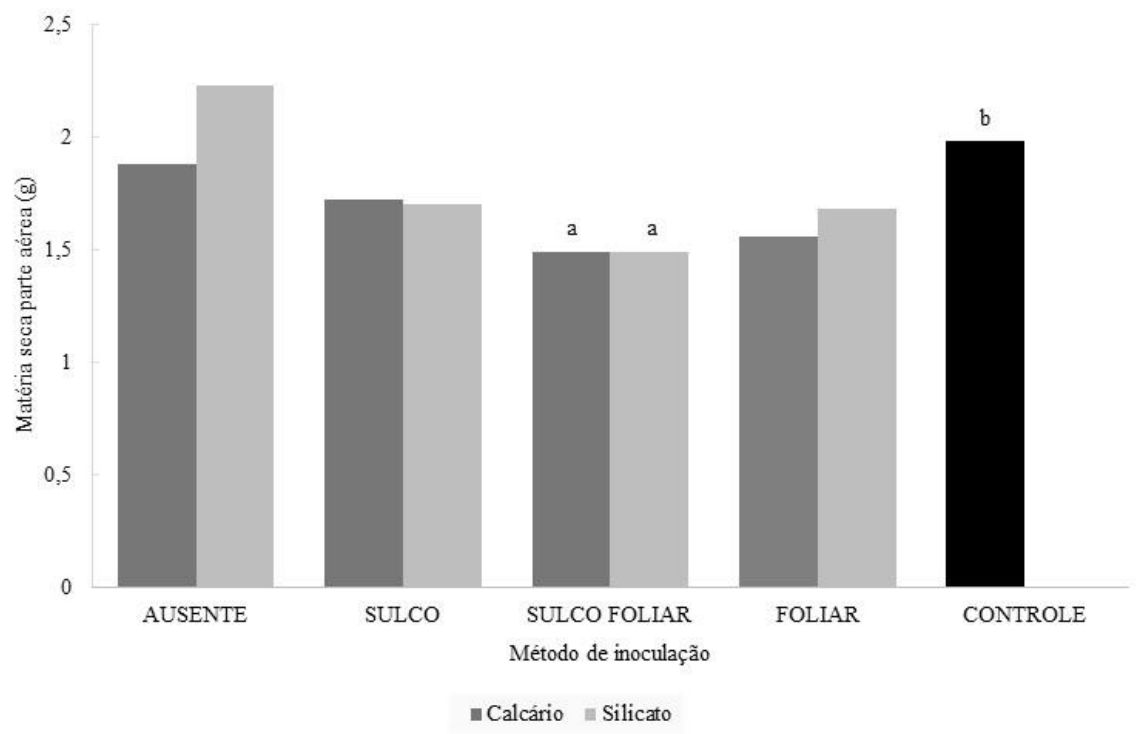

Médias com letras diferentes entre colunas diferem significativamente do controle pelo teste de Dunnet $(\mathrm{p}<$ $0,05)$.

Figura 3. Matéria seca de parte aérea de trigo em presença de calcário e silício, associado aos métodos de inoculação com Azospirillum brasilense.

Cultura Agronômica, Ilha Solteira, v.26, n.3, p.393-405, 2017 
Como consequência, o decréscimo na produção de perfilhos, pode ter desencadeado a diferença observada na produção final de matéria seca da parte aérea (Figura 3).

Fukami et al. (2016) verificaram que a inoculação com elevadas doses de Azospirillum brasilense, inibiram o crescimento de plantas de milho e trigo, consequência da abundancia bacteriana no sistema radicular, que pode ter intensificado a secreção de tais hormônios e comprometido o crescimento das raízes, contrariando os resultados do estudo, que não verificou diferença significativa para a variável (Tabela 1).

Efeitos negativos similares com alta concentração de Azospirillum foram observadas para trigo por Bashan (1986), que verificaram resposta decrescente das plantas quando a dose de Azospirillum aplicada supera a concentração de $10^{5}-10^{6}$ células viáveis por $\mathrm{mL}$. Por outro lado, Fallik et al. (1988), verificaram resultados insatisfatório para milho quando a concentração da Azospirillum atinge $10^{9}$ células viáveis por planta.

Diante das informações, os resultados evidenciam fortemente que o sucesso da inoculação com Azospirillum brasilense em trigo, precisa ser revista, especialmente no que se refere à estirpe envolvida, a forma de veiculação da bactéria e às doses de inoculação, para não interferir sobre o desenvolvimento da cultura e assegurar o seu máximo crescimento.

\section{CONCLUSÃO}

A inoculação via sulco e foliar promove o acumulo de nitrogênio na parte aérea, em contrapartida, provoca decréscimo na produção de matéria seca da parte aérea e número de perfilhos por planta.

O silício incrementa a altura de plantas de trigo, melhora a eficiência de absorção de nitrogênio na parte aérea e não interfere no desempenho da Azospirillum brasilense, independente do método de inoculação, podendo ser empregado como insumo adicional à cultura.

\section{REFERÊNCIAS BIBLIOGRÁFICAS}

ALCARDE, J. A.; RODELLA, A. A. Qualidade e legislação de fertilizantes e corretivos. In: CURI, N.; MARQUES, J. J.; GUILHERME, L. R. G.; LIMA, J. M.; LOPES, A. S.; ALVARES V., (eds). Tópicos em Ciência do Solo. Viçosa: Sociedade Brasileira de Ciência do Solo, 2003. cap. 3, p. 291-334.

ALVES, J. E. D. População, desenvolvimento e sustentabilidade: perspectivas para a CIPD pós-2014. Revista Brasileira de Estudos de População, São Paulo, v. 31, n. 1, p.219-230, 2014. Disponível em: http://www.scielo.br/scielo.php?script=sci_arttext\&pid=S010230982014000100013. Acesso em: 04 jan. 2017.

Cultura Agronômica, Ilha Solteira, v.26, n.3, p.393-405, 2017 
ARAÚJO, S. C. Realidade e perspectivas para o uso de Azospirillum na cultura do milho. Informações Agronômicas, Piracicaba, n. 122, p.4-6, 2008. Disponível em: http://www.ipni.net/publication/ia-

brasil.nsf/0/8F9920C8D263F94183257A90007D8178/\$FILE/Page4-6-122.pdf . Acesso em: 15 dez. 2016.

ASSUERO, S. G., TOGNETTI, J. A. Tillering regulation by endogenous and environmental factors, and its agricultural management. The Americas Journal of Plant Science and Biotechnology, Lincoln, v. 4, n. 1, p.35-48, 2010.

BASHAN, Y. Significance of timing and level of inoculation with rhizosphere bacteria on wheat plants. Soil Biology and Biochemistry, Oxford, v. 3, n. 3, p.297-301, 1986.

BASHAN, Y.Azospirillum plant growth-promoting strains are nonpathogenic on tomato, pepper, cotton, and wheat. Canadian Journal of Microbiology, Otawa, v. 44, n. 2, p.168174, 1998.

BASHAN, Y.; BASHAN, L. E. How the plant growth-promoting bacterium Azospirillum promotes plant growth a critical assessment. In: SPARKS, D. L. (ed.) Elsevier, Oxford: Advances in Agronomy, 2010. cap. 2, p. 77-136.

BASHAN, L. E.; HERNANDEZ, J.P.; BASHAN, Y. The potential contribution of plant growth-promoting bacteria to reduce environmental degradation a comprehensive evaluation. Applied Soil Ecology, Amsterdam, v. 61, n.1, p.171-89, 2012.

BASSO, S. M. S. Caracterização morfológica e fixação biológica de nitrogênio de espécies de Adesmia DC e Lotus L. 1999. 268 p. Tese (Doutorado em Zootecnia) Universidade Federal do Rio Grande do Sul, Porto Alegre, 1999.

BASTO, J. C. H. A. G.; CAZETTA, J. O.; PRADO, R. M. Materiais corretivos e nitrogênio na nutrição e na produção de matéria seca de cana-de-açúcar cultivada em vaso. Interciencia, Caracas, v. 35, n. 1, p.55-58, 2010.

CANTARELLA, H.; RAIJ, B. V. Cereais. In: RAIJ, B. V.; CANTARELA, H.; QUAGGIO, J. A.; FURLANI, A. M. (Ed.). Recomendações de calagem e adubação para o Estado de São Paulo. 2ed. Campinas: IAC, 1997, 285 p.

CASTRO, G. S. A.; CRUSCIOL, C. A. C. Effects of superficial liming and silicate application on soil fertility and crop yield under rotation. Geoderma, Amsterdam, v. 195196, n. 1, p.234-242, 2013.

COSTA, R. R.; MORAES J. Interação silício-imidacloprid no comportamento biológico e alimentar de Schizaphis graminum (Rond.) (Hemiptera: Aphididae) em plantas de trigo. Ciência e Agrotecnologia, Lavras, v. 33, n. 2, p.455-460, 2009.

COSTA, L.; ZUCARELI, C.; RIEDE, C. R. Parcelamento da adubação nitrogenada no desempenho produtivo de genótipo de trigo. Revista Ciência Agronômica, Fortaleza, v. 44, n. 2, p.215 224, 2013.

Cultura Agronômica, Ilha Solteira, v.26, n.3, p.393-405, 2017 
CUNHA, A. R.; MARTINS, D. Classificação climática para os municípios de Botucatu e São Manuel, SP. Irriga, Botucatu, v. 14, n. 1 , p. 1-11, 2009.

DOBBELAERE, S.; CROONENBORGHS, A.; THYS A.; PTACEK, D.; OKON, Y.; VANDERLEY, den J. Effect of inoculation with wild type Azospirillum brasilense and A. irakense strains on development and nitrogen uptake of spring wheat and grain maize. Biology and Fertility of Soils, Berlin, v. 36, n. 4, p.284-297, 2002.

EMPRESA BRASILEIRA DE PESQUISA AGROPECUÁRIA - EMBRAPA. Tecnologias de produção de soja - região central do Brasil 2012 e 2013. 21. ed. Londrina: Embrapa Soja, 2011. 261 p. Disponível em: http://www.cnpso.embrapa.br/download/SP15-VE.pdf . Acesso em: 10 out. 2016.

EMPRESA BRASILEIRA DE PESQUISA AGROPECUÁRIA - EMBRAPA. Informações técnicas para trigo e triticale - safra 2015. 1. ed. Brasília, DF: Embrapa, 2014. 229 p. Disponível

em: https://www.embrapa.br/documents/1355291/1729833/2015inf+tecn+trigo+e+triticale.pdf/2 05d3919-c572-4410-bc4d-1499b94333ba . Acesso em: 07 dez. 2016.

EPSTEIN, E. Silicon. Annual Review of Physiology and Plant Molecular Biology, Palo Alto, v. 50, n. 1, p.641-664, 1999.

FALLIK, E.; OKON, Y.; FISCHER, M. Growth response of maize roots to Azospirillum inoculation: effect of soil organic matter content, number of rhizosphere bacteria and timing of inoculation. Soil Biology and Biochemistry, Oxford, v. 20, n. 1, p.45-49, 1988.

FONSECA, I. M.; PRADO, R. M.; NOGUEIRA, T. A. R.; BARBOSA, J. C. Macronutrients in marandu palisade grass as influenced by lime, slag, and nitrogen fertilization. Communications in Soil Science and Plant Analysis, New York, v. 42, n. 7, p.844-857, 2011.

FUKAMI, J.; NOGUEIRA, M. A.; ARAUJO, R. S.; HUNGRIA, M. Accessing inoculation methods of maize and wheat with Azospirillum brasilense. AMB Express, Heidelberg, v. 6, n. 3, p.1-13, 2016.

GALVANI, F.; GAERTNER, E. Adequação da metodologia Kjeldahl para determinação de nitrogênio total e proteína bruta. 1. ed. Corumbá: Embrapa Pantanal, 2006. 63 p. (Circular Técnica)

HUNGRIA, M.; CAMPO, R. J.; SOUZA, E. M.; PEDROSA, F. O. Inoculation with selected strains of Azospirillum brasilense and A. lipoferum improves yields of maize and wheat in Brazil. Plant and Soil, Dordrecht, v. 331, n. 1/2, p.413-425, 2010.

HUNGRIA, M. Inoculação com Azospirillum brasiliense: inovação em rendimento a baixo custo. 2. ed. Londrina: Embrapa Soja, 2011. 36 p. Disponível em: http://www.cnpso.embrapa.br/download/doc325.pdf . Acesso em: 06 ago. 2016.

Cultura Agronômica, Ilha Solteira, v.26, n.3, p.393-405, 2017 
KORNDÖRFER, G. H.; PEREIRA, H. S.; NOLLA, A. Análise de silício: solo, planta e fertilizante. 2. ed. Uberlândia: GPSi-ICIAG-UFU, 2004. 34 p.

LIMA FILHO, O. F.; TSAI, S. M. Crescimento e produção do trigo e da aveia branca suplementados com silício. 1. ed. Dourados: Embrapa Agropecuária Oeste, 2007. 34 p. Disponível em: http://ainfo.cnptia.embrapa.br/digital/bitstream/item/38734/1/BP200741.pdf. Acesso em: 18 nov. 2016.

LIANG, Y.; NIKOLIC, M.; BÉlANGER, R.; GONG, H.; SONG, A. Silicon in Agriculture. 1. ed. Dordrecht: Springer, 2015. 775 p.

MA, J. F.; YAMAJI, N. Silicon uptake and accumulation in higher plants. Trends in Plant Science, London, v. 11, n. 8, p.392-397, 2006.

MALAVOLTA, E. Manual de nutrição mineral de plantas. 2. ed. São Paulo: Ceres, 2006. $638 \mathrm{p}$.

MENDES, M. C.; ROSARIO, J. G.; FARIA, M. F.; ZOCHE, J. C.; WALTER, A. L. Avaliação da eficiência agronômica de Azospirillum brasilense na cultura do trigo e os efeitos na qualidade de farinha. Revista Brasileira de Tecnologia Aplicada nas Ciências Agrárias, Guarapuava, v. 4, n. 3, p.95-110, 2011.

MOREIRA, F. M. S.; SILVA, K.; NÓBREGA, R. S. A.; CARVALHO, F. Bactérias diazotróficas associativas: Diversidade, ecologia e potencial de aplicações. Comunicata Scientiae, Bom Jesus, v. 1, n. 2, p.74-99, 2010.

MORO, A. L.; BROETTO, F.; MORO, E. Relação hídrica e teor de clorofila em dois cultivares de arroz submetido à deficiência hídrica e adubação silicatada. Irriga, Botucatu, v. 20, n. 1, p.570-586, 2015.

NABTI, E.; SAHNOUNE, M.; GHOUL, M.; FISCHER, D.; HOFMANN, A.; ROTHBALLER, M.; SCHMID, M.; HARTMANN, A. Restoration of growth of durum wheat (Triticum durum var. waha) under saline conditions due to inoculation with the rhizosphere bacterium Azospirillum brasilense $\mathrm{NH}$ and extracts of the marine alga Ulva lactuca. Journal of Plant Growth Regulation, Saint Paul, v. 29, n. 1, p.6-22, 2010.

PORTUGAL, J. R.; ARF, O.; PERES, A. R.; GITTI, D. C.; RODRIGUES, R. A. F.; GARCIA, N. F. S. G.; GARÉ, L. M. Azospirillum brasilense promotes increment in corn production. African Journal of Agricultural Research, Lagos/Nairobi, v. 11, n. 19, p.1688-1698, 2016.

PRABAGAR, S.; HODSON, M. J.; EVANS, D. E. Silicon amelioration of aluminium toxicity and cell death in suspension cultures of Norway spruce (Piceaabies (L.) Karst). Environmental and Experimental Botany, Oxford, v. 70, n. 2-3, p.266-276, 2011.

RAIJ, B. V.; CANTARELA, H.; QUAGGIO, J. A.; FURLANI, A. M. Recomendações de calagem e adubação para o Estado de São Paulo. 3. ed. Campinas: IAC, 1997. 285 p.

Cultura Agronômica, Ilha Solteira, v.26, n.3, p.393-405, 2017 
SCHULTZ, N.; SILVA, J. Á.; SOUSA, J. S.; MONTEIRO, R. C.; OLIVEIRA, R. P.; CHAVES, V. A.; PEREIRA, W.; SILVA, M. F.; REIS, V. M.; URQUIAGA, S. Inoculation of sugarcane with diazotrophic bacteria. Revista Brasileira de Ciência do Solo, Viçosa, v. 38, n. 2, p.359-371, 2014.

SINGH, S. P.; COOPER, J. E.; FISHER, H. L.; TARRANT, C. J.; LLOYD, T.; BANJO, J.; CORFE, S.; JONES, C. Determining the chronology and components of psychosis onset: The Nottingham Onset Schedule (NOS). Schizophrenia Research, Philadelphia, v. 1, n. 80, p.117-130, 2005.

SLEPER, D. A.; POEHLMAN, J. M. Breeding field crops. Ames: Blackwell Pub Iowa, 2006. 424 p.

SNYDER, G. H. Development of a silicon test for histosol-grown rice. In: Belle

Glade Everglades Research and Education Centre Research Report EV-1991. Belle Glade: University of Florida, 1991. cap. 2, p. 29-39.

ZILLI, J. E.; GIANLUPPI, V.; CAMPO, R. J.; ROUWS, J. R. C.; HUNGRIA, M. Inoculação da soja com Bradyrhizobium no sulco de semeadura alternativamente à inoculação de sementes. Revista Brasileira de Ciência do Solo, Viçosa, v. 34, n. 6, p.18751881, 2010. 